\title{
Editorial
}

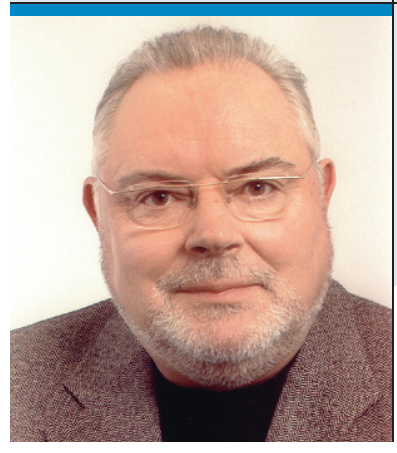

„Die Kassen zeigen sich längst nicht mehr als solidarische Partner, sondern als knallharte und übermächtig gewordene Wirtschaftsunternehmen."

\section{Wie gehabt oder endlich mal umdenken?}

m Streit um die Honorarsteigerung für niedergelassene Ärzte fordern die Ärztekammern unseres Landes den etwas farblos wirkenden Bundesgesundheitsminister Daniel Bahr auf, klare Position zugunsten der Patienten und ihrer Ärzte zu beziehen. Formal gesehen sollten sich Ärzte und Krankenkassen als Vertragspartner ohne Eingriff des Staates einigen. Doch die Politik kann nicht länger zusehen, wie Krankenkassenverbände sich als oberste Sparkommission aufführen und dabei ohne Rücksicht auf Verluste alles plattwalzen, was nicht in ihr pseudoökonomisches Konzept passt.

Dass die Krankenkassen niedergelassenen Ärztinnen und Ärzten angesichts gestiegener Kosten in den Praxen nun eine angemessene Honoraranpassung verweigern, ist von langer Hand und auch erfolgreich vorbereitet worden. Das Märchen vom Arzt, der viel $\mathrm{zu}$ viel verdient, haben wir in allen nur denkbaren Variationen gehört. Nun hat es offensichtlich auch der Schlichter geglaubt und für 2013 lediglich eine minimale Honoraranpassung vorgeschlagen. Diese Steigerungsrate liegt unter den Erhöhungen der Vorjahre - damals allerdings sah die finanzielle Situation der Kassen längst noch nicht so gut aus wie heute.
Die Krankenkassen zeigen sich längst nicht mehr als solidarische Partner, sondern als eiskalte Wirtschaftsunternehmen, die ihre neuerbauten Fassaden mit edelstem Marmor schmücken. Edelstes Interieur ziert Büros und Konferenzräume im Inneren.

Nicht nur das Bundeskartellamt sieht längst die Gefahr zu großer Machtbündelung bei den Krankenkassen. Das muss sich ändern! Nicht nur der Bundesgesundheitsminister ist gefragt, der Kassenmacht ihre Grenzen aufzuzeigen. Politische Entscheider und vor allem der Wähler müssen sich sehr genau überlegen, ob sie ihre Gesundheit in Zukunft in die Hände von dubiosen Kostenoptimierern legen wollen.

Vermeiden Sie erkennbare Grabenkämpfe zwischen Hausärzten und Fachärzten. Es schadet der Ärzteschaft sehr. Entscheiden Sie 2013 mit dem richtigen Kreuzchen in Ihrer Region.

Ein gutes Händchen wünscht Ihnen dabei, Ihr
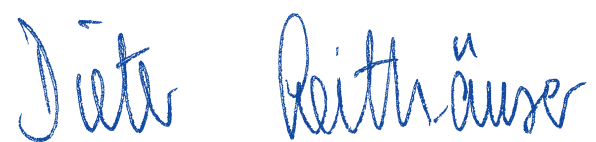